periodicity of tapping and resting is expressed by further fractions showing the frequeney of tapping and the relation of tapping to resting periods. Finally, simple conventions define the arrangement of the panels, a matter which assumes special importancs for the multiple cuts of the so-called slaughter systems by which old trees are drained before replanting. Standard intensity is defined as a half spiral tapped alternate days without rest (that is, equivalent to one quarter cut per day) and the relative intensity of the system is easily arrived at by scanning the formula. As examples: " $S / \mathbf{I}, d / 3$, $4 \mathrm{~m} / 6,89 \%$ " signifies a full-circumference spiral cut tapped every third day for a period of four months in a cycle of six (two months rest), giving 89 per cent of the standard intensity; or " $S / 3, d 2(3 \times 6 \mathrm{~m} / 18)$ $67 \%$ " indicates three panels of one third spiral cut, each one being tapped every second day for six months taking them in rotation. The amount of tapping can be expressed in circumference units (fractional length of cut multiplied by number of tappings), using the actual instead of the ideal number of tappings.

Most rubber estates keep full records which should potentially be a voluminous source of information, but the variables are so many and have in the past been so hazily defined that the scientific value of such records has often proved disappointingly small. Guest's notation will mark a great step forward in the task of making records both intelligible and comparable.

\section{Golf Green Research and the War}

THE revised values which the war places upon various activities have caused the managers of the Board of Greenkeeping Research to review the position of the Research Station at St. Ives, Bingley, Yorks. The experimental plots at this centre have been built up over a period of eleven years, at a cost of more than $£ 26,600$, and have provided valuable new knowledge about the ecological interaction of plants grown in compact formation, and about the practical treatment of greens. Much of their scientific value lies in their long term of treatment, and it is gratifying to learn that they are to be carried on, even if the need for economies should curtail the Station's other activities. It is also useful to remember, in the present intensity of the war effort, that the Station has contributed to a fundamental understanding of grass ecology which could be applied to increase food production on some of the poorer grassland of British uplands. Its researches on pests and diseases of grassland could quickly be turned to the aid of agriculture, and the Station has further adapted itself to war conditions by working on the best methods of pasturing sheep on golf courses, and giving advice upon minimum upkeep during the present difficult times.

\section{Practical Applications of Horticultural Research}

Is time of war there is a special need for the dissemination of the findings of scientific research, and in no field is this more true than in agriculture and horticulture. The application of known facts is often more important than the making of new discoveries. Following this principle, the John Innes Horticultural Institution is preparing a series of leaflets embodying in condensed but adequate form the results of some of the most practically important lines of investigation which have been followed in recent years. The first three of these leaflets have already appeared and deal respectively with the John Innes composts, soil sterilization for pot plants and the John Innes soil sterilizer.

Every horticultural grower is aware of the valuable work done by the Institution in devising two standardized composts, one for seed sowing and one for potting. These composts replace the bewildering array of mixtures recommended in horticultural text-books and may be used with success for every class of plant. No less important is the work of the Institution on the sterilization of potting soils, which has amplified and extended that of the Cheshunt Experimental Station. The principles of sterilization as applied to the John Innes composts are outlined in Leaflet No. 2, while No. 3 gives details of the home construction and the use of the specially designed John Innes soil sterilizer.

\section{Prof. Richard von Krafft-Ebing}

Prof. Rrchard von Krafft-Ebing, an eminent German psychiatrist and a pioneer in the scientific study of sex, was born at Mannheim on August 14, 1840. He received his medical education at Heidelberg under Fredreich and at Zurich under Griesinger, and after qualifying at Heidelberg in 1863 spent five years as an assistant in the Illenau Asylum. In 1872 he was appointed professor of psychiatry at the recently founded University at Strasbourg, and in the following year he accepted an invitation to occupy the corresponding chair at Graz, where he remained until 1889 , when he succeeded Leidesdorf at the First Psychiatric Clinic at Vienna. In 1892 he succeeded Meynert at the Second Psychiatric Clinic, which he directed until his retirement in 1902. $\mathrm{He}$ died on December 22, 1902.

Kraft-Ebing was equally eminent as a research worker and clinical teacher, and gained a well-merited reputation not only as a psychiatrist but also as a criminologist and neurologist. He is best known for the work entitled "Psychopathia Sexualis", of which the first edition appeared in 1886 and the seventeenth posthumously in 1924. It was translated into English, French and Italian. His other works were "Melancholie" (1874), "Lehrbuch der Psychiatrie" (1879) which was translated into English and French and went through seven editions, and "Eine experimentelle Studie auf dem Gebiete des Hypnotismus" (1888), which was also translated into English. At the International Medical Congress at Moscow in 1887 he read an important paper on the causation of general paralysis which, as the result of his own experience, he proved to be the joint product of "syphilization and civilization". He was an honorary member of the medico-psychological societies of London, Paris, Rome, Amsterdam, Moscow, New 
York and Chicago. A monument was erected to him in Vienna in 1908, when an address was delivered by his successor, Prof. Wagner von Jauregg.

\section{Palæozoic Coral Genera}

A complete list of the Palæozoic coral genera has been carefully prepared, correctly named, and supplemented by references to authors, synonyms, localities and published works ("Index of Palxozoic Coral Genera." By William Dickson Lang, Stanley Smith and Henry Dighton Thomas. Pp. vii +231 . London: British Museum (Natural History), 1940. 15s.). Genotypes are arranged in the alphabetical order of the trivial names, followed by the generic name and its author. In the list of literature it is useful to have a record of the genera described in each work. Dr. Lang presents the list as the foundation of future work on the phylogenetic classification of the corals. Although he examines critically the gradations and trends among Tabulate and Rugose corals, he and his collaborators leave the interpretation of the facts to others. The most laborious part of the task has, however, been performed for them. More than fifty generic names are pre-occupied by members of other phyla, and of the corals themselves, nearly twenty names are nomina nuda. This sifting and purifying should be of lasting benefit to workers on the group.

\section{Intelligence among Australian Aborigines}

THE difficulties of applying intelligence tests to primitive peoples with a view to comparative study are notorious, and much ingenuity has been emr loycd in devising tests which are immune from the vitiating factor of differences in the cultural background of the individuals or groups which it is sought to compare. The pioneer work of Dr. S. D. Porteous among Australian aborigines may be recalled in this connexion. Even more remarkable results, however, have been obtained by a recent expedition to the north-western regions of the Continent, sent out by the University of Western Australia, and consisting of three members of the Psychology Department, Mr. N. G. Trayten, Dr. D. W. McElwain and Dr. H. L. Fowler. Under the advice and with the cooperation of Dr. D. S. Davidson, assistant professor of anthropology in the University of Chicago, experiments were made in the application of intelligence tests which had not previously been tried with the Australian aborigines.

Not only was it desired to determine whether these tests were likely to prove more suitable for work with primitive peoples than those generally in use, but also whether they appeared to confirm the low estimate of aboriginal intelligence afforded by previous investigations. In a preliminary report on the work of the expedition, Dr. Fowler (Australian $J$. Ser., 2,$5 ; 1940$ ) records that, of the various tests applied experimentally, the Alexander Passalong test, involving the arrangement of coloured blocks in boxes, the Ferguson form koards, in which insets have to be placed in proper position, and the cube construction test, proved the most suitable, the second being the most satisfactory. Eighteen males and thirteen females were tested. They were of different ages, all but four being adults. In the results the interesting point lies not so much in the average mental age attained as in the range over which the scores spread, while considerable variation was noted in the different tribes. Still more remarkable is the fact that eight of the subjects in one test and five in another scored a mental age of fourteen or over, which indicates that they are at least at or above the level of the average white adult. From these results, which are in agreement with opin ons expressed by squatters as to aboriginal abilities, Dr. Fowler draws the conclusion that further investigations should be undertaken in order that, if these preliminary results are confirmed, steps may be taken to foster the development of such abilities.

\section{Roadwork and Bridges in Hungary}

Following its established custom, the municipal administration of Budapest has again called for tenders for dust-proofing the macadamized roads in the city. According to Roads and Road Construction of July, the proposal was to treat 522,000 sq. kilometres of roads with oil while the remaining 320,000 sq. kilometres of road requiring dust-proofing treatment would have been treated with tar. The bids proved that the price of oiling would have been one third higher than last year, while contractors also insisted on various disadvantageous clauses and conditions. The municipality has therefore decided to apply dust-proofing treatment to a total of $550,000 \mathrm{sq}$. kilometres of road surface only, using tar throughout. The Ministry of Commerce has issued a series of important commissions for the construction or reconstruction of roads and for two new bridges spanning the Danube and the Tisza respectively. The total commissions amount to well over seven million pengoes.

The new bridge over the Danube at Medve will cost more than two million pengoes, while that over the Tisza, in the Hungarian lowlands, will cost nearly 860,000 pengoes. The Danube bridge will be erected by the Hungarian Waggon and Machine Factory, while that on the Tisza will be built by Ganz and Company, of Budapest. The number of road contracts so far allotted is fourteen, and they have been awarded to the same number of different firms, partly to joint stock companies and partly to individuals. The majority of the roads will have concrete surfaces, although a few will have stone surfaces. The total amount of the fourteen orders is about 500,000 pengoes.

\section{Swiss Postal Railway}

IT is stated in the Bulletin of the Oerlikon Co. that an underground railway has recently been built in Zurich for the conveyance of letters and express packets between the branch post office at the main railway station and the Sihl post office, which are about three quarters of a mile apart. The railway is practically automatic. A driverless electric track is set in motion by pressing a push button on the main 